\title{
The Four Dimensional Design and Application of Experience Bank
}

\author{
Mengxin Qi \\ IBG Digital Banking, DBS Bank (China) Ltd, Shanghai, P. R. China
}

Email address:

mengxin.qi@yahoo.com

\section{To cite this article:}

Mengxin Qi. The Four Dimensional Design and Application of Experience Bank. International Journal of Economics, Finance and Management Sciences. Vol. 4, No. 5, 2016, pp. 284-291. doi: 10.11648/j.ijefm.20160405.18

Received: May 28, 2016; Accepted: September 28, 2016; Published: October 13, 2016

\begin{abstract}
This paper discusses that under the background of experience economy, how can traditional banks transform and upgrade their environments, services, products and marketing through cloud computing, big data, mobile communication, social network, and Internet of Things, so as to create quality customer experience.
\end{abstract}

Keywords: Bank, Experience, Sharing, Cloud Computing, Big Data

\section{Introduction}

Twenty years ago, the founders of Strategic Horizons LLP, B. Joseph Pine II and James H. Gilmore published in Harvard Business Review an article titled Welcome to the Experience Economy [1] that claims "Welcome to the emerging experience economy", and had a systematic discussion on "experience economy" in their book titled The Experience Economy [2]. They hold that "an experience occurs when a company intentionally uses services as the stage, and goods as props, to engage individual customers in a way that creates a memorable event", which lays a solid conceptual foundation for "experience" from the perspective of economics.

Giants most sensitive to such trend in this age have responded to it quickly and carried out a series successful business events focusing on customer experience. The globally dominant Microsoft XP system, the popular hypermarket of IKEA, the cozy Starbucks cafe, and the cutting-edge Apple Stores initiated by Steve Job, have achieved huge success by providing their customers with extraordinary experience.

With the arrival of experience economy, banks have developed from traditional banks, to digital banks, to experience banks now. Zhao Zhihong, the President of Strategic Development of Bohai Bank, highlighted in his article "Appreciate Differences - Rebuilding Customer Experience in A New Era of Ecosystem" [22] that in the "Internet+" new era of ecosystem, customer experience is tangible and can been seen and touched in front of customers, thus its influence is increasingly obvious. Therefore, customer experience has become one of the core competitiveness of the banking business. Only through the innovation of product and service values can banks reshape the customer experience journey.

However, the customer experience provided by traditional banks is usually far from satisfactory. For example, cold and featureless ATMs are used to meet only the customers' most basic demands for deposit and withdrawal of cash but their emotional demands. Another example is that services provided to most customers are homogenous. These deficiencies can be fixed by banks aiming to provide quality experience for their customers. As Jon Campbell, the Innovation Director of Continuum Institution, talked in the second " $21^{\text {st }}$ Century Touchstone Financial Design Award" activity [23], financial institutions that only focus on projects with the highest profit margins and do not take active measures to rebuild the customer experience will be hard to survive in the highly competitive market.

Only when banks dig deep into the customers' needs based on customer experience and satisfy these needs with technical means, can they figure out truly applicable solutions in the experience economy.

\section{Application Review}

When it comes to traditional banks, the mass often have the first impression of number, calculation and boredom. However, the banking industry has been quietly transformed 
by Internet technologies and thinking. Influenced by the trend of experience economy, consumers' demands for banks have switched from "passiveness" to "activeness", from "standard" to "individuality", from "product" to "experience". These changes have forced the banking industry to transform and upgrade focusing on "experience bank".

\subsection{Practice and Development of Foreign Experience Bank}

In terms of environment, according to the reports of Shanghai Financial News [3], Umpqua Bank, a leading community bank in the United States, highlights the elements of cafe and retail store and individuality in its new outlets. The area, layout, appearance, service procedures and etc. have been transformed to create outlets that are in stark contrast to those of its peers and provide brand new experience for its customers. The new generation smart ATM, "Bank in a Box" of Citibank almost replaces all of its transitional outlets by providing services such as bank account opening, loan application, credit card and banker's notes issuance.

In terms of services, the General Manger of the Greater China Region of IBM, Wang Tianyi published an article titled There May Be No Bank, But Always Financial Services [4] which says that DBS is the first company that introduces cognitive computing into the banking industry. After more than one year of researches with IBM and Watson, DBS launched a smart system in the first half of 2015 to assist investment consultants in analyzing customers' needs more precisely and putting forward customized investment suggestions.

In terms of products, Wang Xiaowen mentioned in Strategic Research on Retail Business of Excellent International Banks [5] that the Bank of America treats the mass and SMEs as its most important customers, providing small-amount loan of as less as 25 dollars. Moreover, it creates a revolutionary service, Keep the Change, meaning that for each Visa card purchase the customers make, Bank of America rounds up the amount charged to their account.

In terms of marketing, when introducing the experience marketing of HSBC, Yang Misha [6] mentioned that HSBC has incorporated the pyramid model in customer relationship marketing, dividing its customers into seven categories based on customer lifetime value: top-level, high-level, terminal, low-level, inactive, potential, and attention. In this way, the best resources are allocated to establish, maintain and develop relationship with top-level customers, and the best customers are given experience management.

\subsection{Practice and Development of Domestic Experience Bank}

In terms of environment, according to the reporter Jia Yingying of China Finance [7], Hankou Bank is the first experience bank that utilizes RFID chip and Kinect motion capture and other technologies to create an environment that allows customers to see, hear, use, touch, feel and participate. Beijing Branch of ICBC puts efforts in not only creating offline environment, but also coordinating and integrating its e-bank, mobile bank, WeChat bank, and self-service channels to provide customers with integrated $\mathrm{O} 2 \mathrm{O}$ experience.

In terms of services, according to the reports of Xinhua Net [8], the "Pocket Bank" of Ping'an Bank has used e-map to display the waiting time of different outlets for the first time for the customers to learn about how busy each outlet is. Moreover, the "Super Counter" researched and developed independently by the Agricultural Bank of China can handle 55 services of 8 categories which account for more than $80 \%$ of $A B C$ 's individual non-cash services.

In terms of products, China Merchants Bank introduces on its official website [9] that "Yi-Shan-Tong", its financial product, integrates bank cards with cellphone, thus leading the industry into the cardless age. Huaxia Bank upgrades its "Bank around You" to "Bank on You", being the first domestic bank that launches watch bank to provide financial services. The customers can access to financial services such as balance inquiry, transfer, outlet navigation, and information search by touching the smart watch on their wrist.

In terms of marketing, Jia Yingying mentioned in The "Smart" Transform of Banking Industry [7] that Tianjin Branch of the BOC introduces user interactive technologies and experience devices to attract customers to browse, try and compare different financial products accompanied by specialists who would introduce and recommend such products. In this process, these experience devices smartly monitor the customers' responses and collect relevant data to help the bank understand their behavior patterns and potential needs, so as to achieve the purpose of "recommending suitable products to the appropriate customers in proper time through proper channels".

\subsection{Problems and Challenges}

Experience bank is not about optimizing a single channel or product, but about re-orienting and planning the bank's environment, services, products and marketing from the dimensions of all-channel coordination, big data application, procedure recreation, etc. based on the customers' needs and experience.

From the perspective of practices of domestic and foreign banks, there is not a bank which has established an "experience bank" comprehensively and systematically. Therefore, this paper aims to design the overall structure of an experience bank from four dimensions: environment, services, products, and marketing, and cases are given to illustrate the application of the design.

\section{Establishment of the Environment of Experience Bank}

\subsection{Humane Experience in a Comprehensive Environment}

A comprehensive environment providing humane experience can not only transfer the value of the bank to customers subtly, but also impress the customers who in return will be more prone to accept the bank's products and services. 
In terms of the design of the comprehensive environment of experience bank, the following three aspects deserve attention: theme, image and technology.

\subsubsection{Theme}

The theme of environment can be developed through many aspects. Local historical characteristics, for example, may be used in the decoration of a bank hall, such as, Terra Cotta Warriors style in Xi'an, "edges of the heaven, corners of the sea" style in Hainan. In addition, in festivals such as Valentine's Day, efforts could be made to design the bank outlets and staff images to keep pace with the times and show the milk of human kindness with chocolate, golden cards, jewels, etc., building the atmosphere of love.

\subsubsection{Image}

In establishing the image of a bank, themed environment is not enough. One or a series of more specific measures are required, such as the design of mascot, the selection of spokesman and the connotation of the bank's story. The stronger the connection between the bank and the image it creates, and the more vivid the image is, the more stable the customer experience will be. For example, an outlet promoting mortgage loan may display a ladder, a bucket of paint and a brush in the outlet to show the customers that it can not only provide mortgage loan for them, but also help them with decoration of the home if needed.

\subsubsection{Technology}

In the implementation stage after finishing the design of theme and image, digital exhibition hall and hologram technologies can be used to create the desired experiential bank environment. Digital exhibition hall technology has been put in use by many organizations, most of which use a variety of interactive screen for interaction and information display. Hologram, a kind of new optical imaging technology, can be found in many classic science fiction movies. In recent years, it has been widely used in people's lives and brought richer experience with its vivid visual effect and low cost of replication. In bank, for example, hologram technologies can be used to display the bank's mascot wishing the customers happy new year in the bank hall during Spring Festival, or used in the communication between customers and their wealth management consultants.

\subsection{Interactive Experience in a Digital Environment}

Technical transform of the environment goes far beyond the above-mentioned examples. With the development of Internet, it becomes increasingly important for banks to create a digital environment where a more essential function is fulfilled: real-time interaction with customers. This section will describe the flow structure of the digital environment, and explore how to achieve effective interactive experience with technologies.

\subsubsection{Perception}

In order to achieve the interactive experience in the digital environment, the first step the bank should take is to improve its power of perception of the customers. The bank has to perceive customers' needs, the scenarios that they are in during the communication, and even their moods; a "digital reception desk" can serve as a vital "sensory organ" of the bank.

Digital reception desk is the umbrella name of the access to the systems that enables communication for customers with the bank, including not only reception desk in the outlets of the bank, external self-service equipment for transaction, payment and deposit, access to mobile bank and online bank, but also the access to the financial services required by the cooperating companies of the bank, such as social networking companies and trade companies. When authenticating customer identity, different methods for authentication may be adopted for different types of access. For the mobile terminals, one-time password sent via SMS together with password input via speech recognition of microphone can be used for authentication; for external self-service equipment, facial recognition systems, iris recognition, etc.; for PC terminal, private key, digital certificate, biological recognition through external devices.

\subsubsection{Response}

After perceiving the customers' information, the reception desk should respond quickly to their requests. The responses can be roughly divided into two types: "artificial response" and "machine response". The former can expand the radius of services provided by one single person by taking the advantages of voice, video, hologram and other technologies; while the later requires the support of the core processor of the intelligent business procedure system.

\subsubsection{Analysis and Prediction}

At the same time of response, the reception desk also timely send the customers' information to the back-office data processing center which after integrating, analyzing and predicting, abstracts the user portrait from the data and return the portrait to the reception desk along the original route.

Gartner's Bimodal IT is of reference value for backstage data processing of the bank [10]. The small data analysis and processing systems distributed in the branches (the "cerebellum"), are mainly used to respond to customer demand quickly, primarily consisting of "short-distance running" thought; the large data analysis systems distributed in the head office (the "brain" ) are mainly used to maintain the sound operation of commercial banks, primarily consisting of "long-distance running" thought. The "cerebellum" is the "innovation laboratory" of the bank, and gradually replaces part of the "brain" without affecting its functions. The combination of cerebellum and brain maintains the flexibility as systems of Internet enterprises and the robust style as traditional banks.

\subsubsection{Real-time Interaction}

"Real-time interaction" means that a bank should be able to respond quickly to the customers' requests not only within the range of its services, but also when they are communicating with other companies to provide the customers with the appropriate financial services. To achieve these purposes, a bank is required to participate in the sharing economy circle 
and highly integrate resources of each industry chain, so as to carry out multi-layer strategic and business cooperation. For example, a bank may cooperate with auto $4 \mathrm{~S}$ shops by providing real-time professional financial services in the process of purchase, shortening the time required for car loan application, review, and fund disbursement to half an hour.

\section{Establishment of the Services of Experience Bank}

\subsection{Visualized Services}

If a bank wants to sell its products, it must consider customer services as retail. In other words, it should exhibit its products for the customers to see, touch, and learn about, so that the customers are attracted to "visit" the bank, hence opening up the business opportunities for financial services.

Information visualization can demonstrate abstract information in intuitive visual ways that allow customers with different needs to observe and process information with their sight and perception, and finally find out the relationship between and the hidden meaning of the information. For example, Umpqua Bank sets up a "Discover Wall" in its outlets to guide the customers to learn about the financial products of the bank through advanced technological means, and an "Inspiration Wall" that offers a variety of banking product simulation and prediction, as shown below [11].

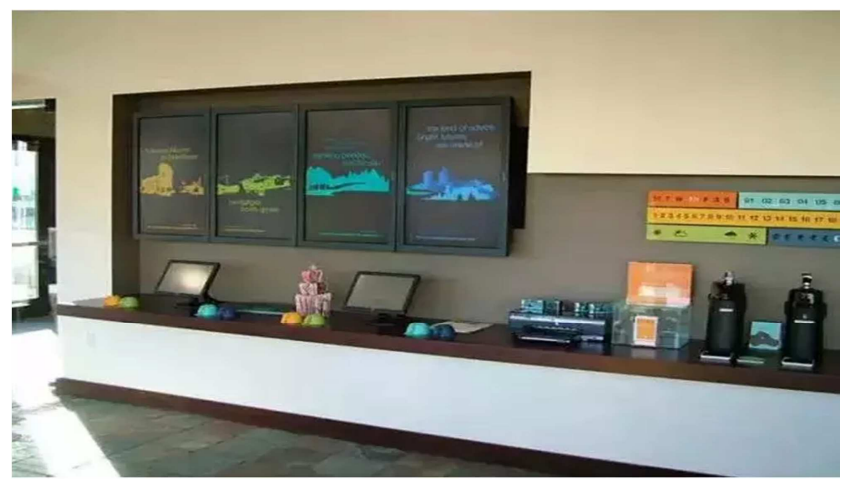

Figure 1. Discover wall of Umpqua Bank.

However, the difficulties of information visualization of banks lie in not only the huge amount of data in the financial industry, but also that every datum is of certain reference value. Take option and other financial derivatives as an example, TBs of data from all around the world is generated each year. Therefore, a bank should establish a system for visualized services from the following three aspects: mapping, interactive technologies, and social elements.

\subsubsection{Mapping}

In short, the essence of visualization technology is the process of mapping abstract data into visual forms. Algorithms are required for the process of mapping, such as clustering algorithm, the K-means, support vector machine (SVM) and SOM algorithm which are commonly used in data mining. Through various forms of quantification, these algorithms demonstrate the internal logic that is unable to be observed by human eyes. However, in the era of big data, complex algorithms consume a huge amount of computer resources, and the customers' personal computer resources cannot satisfy the need. Therefore, banks have to set up their own data center equipping with their own central computers. In this way, when a customer calls the visualization resources through an individual channel, the central computers will operate quickly and feed the results back to the vision processors which, as the secondary processors, communicate with the customer terminal, dispersing the pressure on computing and interaction in the whole process of mapping.

\subsubsection{Interactive Technologies}

Interactive technologies are customers' control of a visualization system, wherein navigation, selection, filtering and knowledge granularity are the most commonly used operation. "Navigation" refers to customers' action to quickly find out the information needed, involving switch of data levels and data contents; "selection" refers to the action that customers respond to the system, and if they want to view the details of a certain content, lightening up and coloring data can be used; "filtering" means that if there is too much distracting information, one can choose to view key information or filter out contents not needed; "knowledge granularity" refers to the guidance of different levels given by the systems to customers of different levels of knowledge reserves.

\subsubsection{Social Elements}

A visualization system should not be limited to the communication between customers and a bank; it should also provide a social platform and financial data community for customers to communicate, which will add more resources to the banks' reserves of knowledge. For example, a famous Q\&A App, "Zhihu", has established a huge but flexible community with a large number of knowledge creators and receivers through texts, images and videos.

\subsection{Customized Services}

Customers' pursuit of customization will become a rigorous screening of the numerous participants in financial market. The generalized designs of banks gradually fail to satisfy the needs of customers who are becoming more and more "picky". Therefore, the customized designs that can quickly and perfectly support the banks' products and services are the key to adapt to customer experience in the Internet age for banks. Next, this section will discuss the customized services of banks from the following two aspects: "user portrait" and "customization system".

\subsubsection{User Portrait}

Banks have a huge customer base. Customers of different ages, incomes, occupations, and assets have various needs for financial products. As a result, banks need to analyze and understand their customers through "user portrait" so as to find out the target customers and design products according to their needs. This is the basis of customized services.

Moreover, banks hold abundant customer data, including 
data types, data volume and various systems. It is not necessarily better to involve as many dimensions of data as possible in the user portrait. The dimension of data should be both simplified and closely related to business, and not only convenient for screening but also convenient for further operation. If one was to break down the work of user portrait, he/she can basically follow these five steps: first, organizing and centralizing data related to portraits; second, finding out data closely related to the business scenario; third, classifying and labeling the data; fourth, introducing external data according to business requirements; fifth, screening customers according to business requirements.

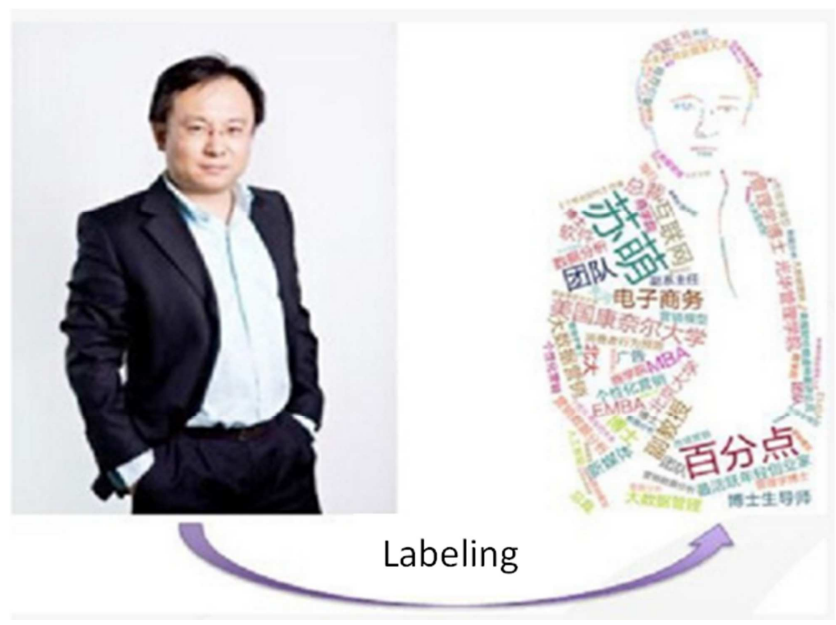

Figure 2. Classifying and labeling customer data.

\subsubsection{Customization System}

User portrait prepares for customization by handling and integrating customer data. The main content of this section is the design of customization system, providing simple approach to the realization of customized services. The building of customization system requires three bases: cloud of product, interactive system, and pricing system.

Cloud of Product. As the cloud stores many information and data of the banks' all types of products, only when the overall way of thinking and classification of the cloud of product are well planned, and when there are enough detailed resources in the cloud, can the system be able to provide the customers with suitable products based on the most humane considerations with the most efficiency. Cloud of product is the most essential resource in the customization system.

Interactive System. When there are enough resources in the cloud of product, the interactive system will accurately perceive the intention of customers' operations, search for the most matching products in the cloud, and then recommend them to the customers. To fulfill the function of the system, seamless integration with intelligent terminals is often required. With the development of the Internet of Things, intelligent terminals include not only intelligent communication terminals such as cellphones, tablets, but also glasses, watches, bracelets, earrings and other wearable devices. For instance, Xiaomi bracelet can constantly monitor the customer's sleep and exercise without any operation, achieving the purpose of real-time interaction with customers.

Pricing System. As a support for the cloud of product and the interactive system, the pricing system should consider not only the costs of products and services, but also the customer value; the former needs the planning of the cloud of product, while the later requires the support of user portrait. Based on the information provided by the user portrait, the system will automatically determine the customers' level of consumption and value, so as to provide customers of various levels and values with different services at different charges.

Take "step interest rates" as an example. The rating of customer value is determined by calculating all kinds of information, such as amount of deposit, frequency of card swiping, credit card consumption, with different weights assigned on them. In brief, customers can be divided into the following four types: customers of high value and high loyalty should be offered the utmost attention and the reward of benefits; customers of high value and low loyalty should be offered certain preferential treatment and their subsequent responses should be observed; customers of low value and high loyalty should be offered appropriate preferential treatment and attention should be paid to emotional connection with them; customers of low value and low loyalty should be mined regularly to see if there is any potential high value customers.

\section{Establishment of the Products of Experience Bank}

\subsection{Internet + Financial Products}

This section will focus on the design of experience banking products that customers are most frequently exposed to: wealth management product, payment product, and credit product.

\subsubsection{Considerate Wealth Management Products}

The wealth management products of a bank should be adjustable to user data so that personalized wealth management plans are tailor-made and presented to each individual customer. Inspired by the wealth management product "golden egg wealth management" [12], the bank may determine a base interest rate for the demand deposit product, for example, $8 \%$, and then adjust the rate applicable to each account based on the liquidity risk of it (including the customer's liquidity preference, deposit/withdrawal frequency and etc.). Finally, different accounts would be offered different interest rates.

At the same time, to save the customers' trouble of choosing from too many products as it may jeopardize the customer experience, the bank may present only one demand deposit product to a new user when he/she first visits the page, and then gradually push different customized fixed income products to increase the customers' return on investment as their time and data accumulate on the platform.

In brief, the bank uses the demand deposit product to attract customers and collect their data, which would later be 
analyzed for a more precise push of various wealth management products to customers. Maybe in the future, the users do not have to make any decision and the system will automatically recommend the right products for them; all the users need to do is to transfer money to the platform.

\subsubsection{Open-Ended Payment Products}

The payment products offered by a bank should be centered on software and open to hardware devices, making use of the numerous hardware devices produced by Internet companies and manufacturers "for its own purposes" to fully keep up with the trend of Internet of Things.

In terms of hardware, from the bank passbook in the 1980s, the magnetic stripe card in the 1990s, to the IC card in recent years, these simple card "carriers" can no longer provide a higher level of customer experience. With the popularity of the Internet of Things and the rise of wearable devices, each portable smart device can be used as a simple and convenient payment tool, leaving the cards that do not support real-time communication useless.

In terms of software, from NFC, QR code, acoustic wave, photon, fingerprint, iris, vein payment, to the newly developed thought payment, a variety of payment technologies have emerged. The bank may incorporate different payment technologies into its payment products based on different hardware devices as well as divergent scenarios of consumption, bringing diversified payment experiences to customers.

\subsubsection{Mobile Lending Products}

Different from traditional business process, mobile lending model reliant on credit risk profile may replace hard-copy application forms to some extent and significantly streamline procedures of small-amount loans, contributing to a safe, efficient and convenient experience for the customers.

As for how to establish credit risk profiles, the first thing is to understand the characteristics of the data possessed by the bank. According to the reports of China Finance [13], based on the business data of 150,000 customers accumulated since 2011, ICBC combined the operations of small and micro businesses and the characteristics of personal accounts, complemented them and verified them against each other. Built on that, ICBC has reconstructed the mode of default risk identification, and established consistent risk acceptance criteria for personal business loans and small and micro enterprises loans.

On the basis of that, the bank may cooperate with Internet companies and access to third-party credit rating, anti-fraud and other credit products, to further refine its credit risk profiles and to provide more effective support and protection for the development of the bank's credit business.

\subsection{Internet of Things + Financial Products}

In this era when all things are connected, the scenarios that customers are put in can be captured through various sensors and terminals and utilized by enterprises. As the giant in the financial sector that has a remarkably wide business coverage, bank will play a vital role in the scenario of Internet of Things if they know how to cooperate with different kinds of companies. This section will discuss the two fields most closely related to the daily lives of customers: "Internet of Vehicles" and "Internet of Homes".

\subsubsection{Internet of Vehicles Finance}

As the "giant" in the scenario of Internet of Things, the financial services related to the Internet of Vehicles will no longer be confined to car loans and car insurance. This paper endorses the definition of Internet of Vehicles finance in the book, Real-time Intelligent Bank [14] by Zhao Zhihong, who observed that "Artificial intelligence, mechatronics, navigation, satellite systems and financial services interact with each other inside the vehicle, to create an emerging finance featuring identification, confirmation and delivery of financial opportunities, and early warning and control of risks".

Internet of Vehicles consists of a series of companies. As giants in the industry of financial services, banks should seize the opportunity to take the lead in integrating resources of companies in the automotive industry chain. Banks should first identify potential car buyers through the detailed user portraits and offer them corresponding guidance. Next, banks would provide customers with personalized services using the customization system that is connecting in real time to the enterprise resource pool on the automotive industry chain. The car prices may also be indicated through the customized pricing system in real time. If the customer has the intention to buy cars, he/she can make an appointment with a physical $4 \mathrm{~S}$ store for a test drive. When the customer makes a decision to buy, the bank will push to him/her car loans and car insurance services in real time, or even car accessories coupons that will, lead them to another industry chain.

A real-time, intelligent servicing capacity for "Internet of Vehicles finance" would only become possible if banks lay a solid foundation for components and digital facilities, and attain cross-industry integration in business processes and data with automobile manufacturers, automotive service providers, insurance companies, and commercial banks.

\subsubsection{Internet of Homes Finance}

Unlike the concentration of the Internet of Vehicles, the diversity of products in the Internet of Homes imposes greater challenges to integrate the resources of different industry chains. Therefore, banks must firmly control the payment process, incorporating the service in the form of digital wallet into the customers' consumption behaviors, and adhering to the strategic position of "focusing on software and opening to hardware devices".

Take intelligent refrigerator as an example. When the customer buys a refrigerator, the bank can quickly provide an installment loan; when the refrigerator begins to operate, the bank can use the digital wallet software in the refrigerator to monitor payment request and other information from the refrigerator system in real time. For example, if there are not enough supplies of food in the refrigerator, the refrigerator will request for purchase from merchants and the digital wallet will make the payment under the instruction of the system.

In addition to the control of payment, the bank can also 
establish its own "cloud of industry" and cooperate with home furnishings companies to provide customers with various value-added services. Another example is intelligent bathroom. In the future bathroom, HD camera will be embedded in the mirror and connected to the Internet. When the customer stands in front of the mirror, the mirror will automatically scan he/she and then carry out breath test to examine his/her physical health. Relevant information will be transmitted to the big data platform of the bank in real time. In case of any abnormality detected, the platform will immediately search the resources in the "pharmaceutical cloud" established by the bank and integrate them into a whole set of solution that will be sent to the customer's cellphone.

\section{Establishment of the Marketing of Experience Bank}

A renowned scholar Dr. Schmidt pointed out in his book Experiential Marketing that "Experiential marketing redefines and redesigns the way of thinking of marketing by standing on customers' feeling, emotion, thinking, acting and associating." [15] Such way of thinking breaks the traditional hypothesis of "rational consumers", assumes that consumers are both rational and emotional in consumption, and their experience before, amidst and after consumption should be a key reference for companies to formulate marketing plans.

\subsection{Creating Experience with "Community Marketing"}

In today's Internet age, the way people obtain information has been switched from the WeChat "fragmented reading" to the post-WeChat "powdered reading". With the increase in the subscribed official accounts, contacts and chatting groups, reading has gradually become powdered. Users follow the flow of information, but are more difficult to gather.

Among them, strong social relationships driven by interest come to the fore. In the stage of fan economy, as long as customers become users, and users become fans, companies can obtain considerable social dividends. But in the stage of community economy, only when the fans become friends and join the same community, can the companies have the chance to make any profit.

Therefore, banks should invest in "long-tail" users with a wide range of fans on the Internet, and actively cooperate with various Internet companies, end brands, well-known IPs, etc. to establish a cross-platform multi-layer interactive marketing mode.

Specifically, banks may refer to the mode of credit card social platform of CITIC Bank [16] to build a "3 + N" Internet platform. Among them, "3" refers to the bank's official website, mobile WAP website and mobile App; "N" refers to all social platforms that the bank operates, including official Weibo account, mobile QQ public account, WeChat official account, Alipay service window, etc. The official channels and the emerging social service platforms are used to build diversified, convenient and interesting communication channels for users, allowing them to enjoy personalized services provided by the bank in relaxed interactions.

\subsection{Offering Precise Experience with "Big Data"}

Marketing of traditional bank is standard, aimless and passive, and the customers find it hard to have access to personalized services and products they need, and even harder to experience the real value of services and products.

Using analytical capability and connectivity of big data, the bank can promote a "real-time shopping guide" in its offline outlets. Within one second the bank staff interacting with the customer, with the help of real-time touchpoint identification and big data analysis technology, the staff will receive the recommendation for personalized products and services pushed by the "guide". Although in less than one second, the customer data has been collected offline and integrated online, and the final precise intelligent recommendation produced.

Cloud computing technology not only allows the bank to realize the centralization of data, management, prevention and control, and decision-making for each kind of resources, but also enables the customers to choose or customize products and services from the "financial cloud" based on their own needs, hence the achievement of an intelligent and self-service bank.

\subsection{Improving Experience with "Experience Map"}

After a product is launched to the market, how to obtain users' feedback and further improve customer experience in time is what a bank needs to think about. If banks only address product features and attend each module separately, it will be difficult to meet the goal of improving the overall experience. This is especially true under the trend of "connecting people and services". As the overall service experience depends on each point of contact between the user and the product, ignorance of one point may lead to the complete failure of the product. Just like topographical maps are needed in wars, a blueprint is also required for planning and guiding the battle for improvement of experience.

"Experience map" is such a blueprint. It is designed to locate and describe service experience of each stage during the whole process of service, and record, organize and display the experience with graph, including what the user has done and felt in the course of service. In many cases, people try to use it to evaluate services and products, locate the user's pain points and satisfaction points to explore the experience. For example, below is a user shopping process in a supermarket, recorded using the first-person perspective by splitting the task [17].

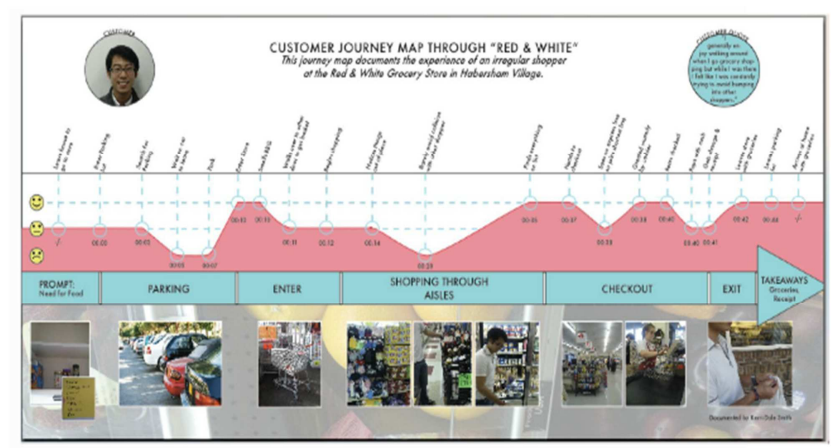

Figure 3. Customer experience map of a supermarket. 
Banks may try to use the experience map to demonstrate in their entirety all the nodes that the user and product interact (as shown below), so as to identify the user's expectations, and then explore the differences between the actual experience and the expectations, which will be addressed in the subsequent optimization of products and services.

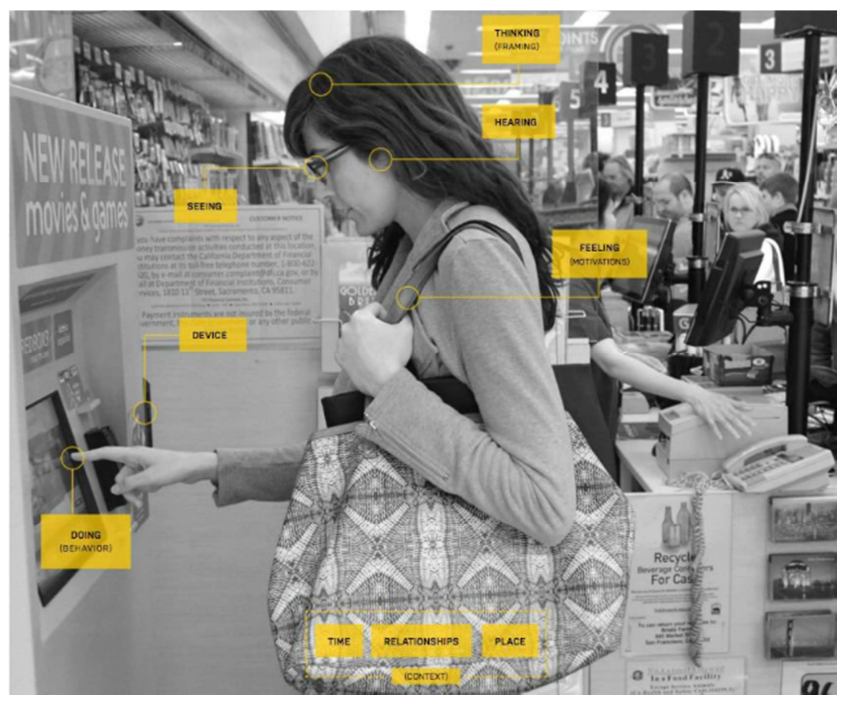

Figure 4. Customer and ATM interaction nodes.

\section{Conclusion and Expectation}

This paper discusses that under the background of experience economy, how can traditional banks transform and upgrade their environments, services, products and marketing through cloud computing, big data, mobile communication, social network, and Internet of Things, so as to create quality customer experience.

However, the construction of an experience bank includes not only the above-mentioned four basic items, but also effective business procedures, open-ended big data platform, financial ecosystem with inter-connecting industries, etc. The demonstration of dazzling technologies and the novel service experience are just the appearance of experience bank which is backed by revolutions in concepts, strategies, and procedures. Every step taken during the process of revolution will make a better experience bank.

\section{Acknowledgements}

This paper is a new research result of the author after the research on digital bank. Comments and suggestions from practitioners in the industry are more than welcome!

\section{References}

[1] B. Joseph Pine II and James H. Gilmore, Welcome to the Experience Economy, Harvard Business Review, 1998, 76 (7/8), pp. 97-105.

[2] B. Joseph Pine II and James H. Gilmore, The Experience Economy, Trans. Y. Xia. Beijing: China Machine Press, 2008.
[3] Small, self-service and platform-based bank outlets is the future trend, Shanghai Financial News, 2015(12).

[4] T. Wang, There May Be No Bank, But Always Financial Services, FT Chinese, 2015.

[5] X. Wang, Strategic Research on Retail Business of Excellent International Banks, The Chinese Banker, 2015(3).

[6] M. Yang and F. Shi, The Pyramid Model and Experiential Marketing, Enterprise Vitality, 2006(12), pp. 42.

[7] Y. Jia, The "Smart" Transform of Banking Industry, China Finance, 2015(7).

[8] Flagship Store of Ping'an Bank: New Concept Leading the Development of Outlets, Xinhua Finance, 2014.

[9] Banks Entering into a Card-less Era, Creating Extraordinary Financial Experience, China Merchants Bank, 2014.

[10] M. Mesaglio and S. Mingay, Bimodal IT: How to be Digitally Agile Without Making a Mess, Gartner, 2014.

[11] Z. Lin and J. Zhang, Analysis of Transform of Physical Outlets: Take Umpqua Bank as an Example, China Banking Industry, 2015(7).

[12] Nvwang Dingding. A Wealth Management Product that May "Understand" the Users Best in the Internet Finance Circle, 36 Krypton, 2015.

[13] H. Yi, Improving the Ability of Risk Management with Big Data, China Finance, 2015(8), pp. 12-15.

[14] Z. Zhao, Real-time Intelligent Bank, Beijing: China Financial Publishing House, 2015, pp. 77.

[15] Schmitt. Experiential Marketing, Beijing: China Three Gorges Press, 2001.

[16] Community Economy, the Next Battle Field where Banks Fight for "Long Tail", Internet Finance Net, 2016.

[17] User Experience, Using "Experience Map" to Capture Every Pain Points of Products, Tuicool, 2015.

[18] S. Zhu, Experiential Marketing and Its Model Structure, Business Economics and Administration, 2003(5), pp. 25-27.

[19] T. Wang and G. Cui, Interpretation and Construction of Experience Economy Against the Background of Economic Form, Economic Management (New Management), 2003, pp. 43-49.

[20] J. Chen, Multi-layer Customer Experience and Experience Life Cycle, Statistics and Decision, 2005 (second half of June), pp. 109-111.

[21] L. Wang and X. Qian, The Definition of Experience Connotation and the Strategy Research on Experience Marketing, Journal of Huazhong University of Science and Technology (Social Science Edition), 2007(5), pp. 62-66.

[22] Z. Zhao, Appreciate Differences - Rebuilding Customer Experience in A New Era of Ecosystem, Modern Bankers, 2015(10).

[23] $21^{\text {st }}$ Century Touchstone Financial Design Award Announced, China Business, 2016. 